\title{
Estado da Arte da Formação de Professores no Brasil"
}

\author{
Marli André* \\ Regina H.S. Simões \\ Janete M. Carvalho* \\ Iria Brzezinski
}

\begin{abstract}
RESUMO: O presente trabalho busca fazer uma síntese integrativa do conhecimento sobre o tema da formação do professor, com base na análise das dissertações e teses defendidas nos programas de pós-graduação em educação do país, de 1990 a 1996, dos artigos publicados em 10 periódicos da área, no período 90-97, e das pesquisas apresentadas no Grupo de Trabalho Formação de Professores da Anped, no período de 92 a 98.
\end{abstract}

Palavras-chave: Formação inicial, formação continuada, profissionalização docente

\section{Oque dizem as dissertações e teses?}

O exame das dissertações e teses defendidas no período de 90-96 mostra que a produção discente quase dobrou nesse período, passando

\footnotetext{
* Esse trabalho faz parte do convênio Anped/Pnud, que teve a intermediação do Inep.

** Professora da Faculdade de Educação da USP, São Paulo.

*** Professora da Universidade Federal do Espiríto Santo.

**** Professora da Universidade Federal do Espiríto Santo.

**** Professora da Universidade Católica de Goiás. Email: iria@netgo.com.br
} 
de 460, em 1990 para 834, em 1996. O número de trabalhos sobre formação de professores, porém, não acompanhou esse crescimento; embora tenha aumentado de 28 para 60 , nesse mesmo período, manteve uma proporção estável de 5\% a 7\% sobre o total da produção discente.

Dos 284 trabalhos sobre formação do professor, produzidos de 1990 a 1996, um total de 216 (76\%) tratam do tema da formação inicial, $42(14,8 \%)$ abordam o tema da formação continuada e $26(9,2 \%)$, focalizam o tema da identidade e da profissionalização docente.

A formação inicial inclui os estudos sobre o curso Normal - $40 \%$ do total das pesquisas -, o curso de licenciatura (22,5\%), e a pedagogia $(9 \%)$, além de três estudos comparados. O conteúdo mais enfatizado nesses trabalhos é a avaliação do curso de formação, seja em termos de seu funcionamento, seja em termos do papel de alguma disciplina do curso. Outro conteúdo priorizado é o professor, suas representações, seu método, suas práticas.

Os estudos sobre formação continuada analisam propostas de governo ou de Secretarias de Educação (43\%), programas ou cursos de formação (21\%), processos de formação em serviço (21\%) e questões da prática pedagógica (14\%). Embora o número de estudos sobre formação continuada seja relativamente pequeno, abrangendo $14,8 \%$ do total de trabalhos sobre formação docente, os aspectos focalizados são bastante variados, incluindo diferentes níveis de ensino (infantil, fundamental, adultos), contextos diversos (rural, noturno, a distância, especial), meios e materiais diversificados (rádio, televisão, textos pedagógicos, módulos, informática), revelando dimensões bastante ricas e significativas dessa modalidade de formação.

O tema identidade e profissionalização docente é pouco explorado no conjunto das pesquisas, configurando menos de $10 \%$ do total das 284 dissertações e teses defendidas, mas emerge com certa constância nos últimos anos. Os conteúdos que se destacam nesse grupo de estudos são a busca da identidade profissional e as concepções do professor sobre a profissão. Aspectos relacionados às condições de trabalho do professor e aos movimentos de sindicalização e organização profissional aparecem só nos últimos anos, mas ainda de forma muito tímida. Questões voltadas a saberes e práticas culturais, gênero e raça são raramente estudadas.

O exame da metodologia utilizada nas dissertações e teses sobre formação docente mostra que 72 pesquisas (25\%) estudam um caso, seja ele um curso, uma disciplina, uma turma, um professor. São, em ge- 
ral, estudos pontuais, voltados ao conhecimento de um aspecto muito particular da formação docente. Outro tipo freqüente de estudos é a análise de depoimentos (14\%), em que o pesquisador faz levantamento de dados com questionário ou entrevista, visando conhecer opiniões, pontos de vista ou representações dos informantes. Também aparecem, com freqüência razoável na produção discente, os relatos de experiência $(12 \%)$, que em sua grande maioria são produções de mestrado. São trabalhos que se propõem a registrar e divulgar uma experiência, não assumindo compromisso explícito com a geração de conhecimentos novos. Com menos ênfase, mas ainda com certo destaque, aparecem os estudos teóricos, as pesquisas históricas, a pesquisa-ação e as análises da prática pedagógica. Muito raros são os estudos do tipo survey, a pesquisa experimental, os estudos de validação de material e os estudos longitudinais.

Em linhas gerais, o exame das dissertações e teses produzidas na década de 1990 sobre formação de professores revela que a maioria dos estudos se concentra na formação inicial, procurando avaliar os cursos que formam os docentes. O curso Normal é o mais estudado. $O$ curso de licenciatura também é alvo de muitas pesquisas, enquanto o curso de pedagogia é pouco investigado. Os conteúdos emergentes nos estudos sobre a formação inicial são os temas transversais, como a educação ambiental, educação e saúde, e drogas.

Embora as dissertações e teses sobre formação continuada não sejam muito expressivas em termos numéricos, elas o são do ponto de vista da abrangência e dos conteúdos investigados, pois cobrem diferentes níveis de ensino, contextos variados, meios e materiais de ensino diversificados.

Identidade e profissionalização docente surge como tema emergente nos últimos anos, e abre perspectivas para questões de grande interesse e atualidade, como a busca da identidade profissional do docente, a relação do professor com as práticas culturais, questões de carreira, organização profissional e sindical, e questões de gênero.

Uma visão geral dos conteúdos abordados pelas pesquisas dos discentes revela que grande parte dos estudos se concentra em análises pontuais de um curso, de uma disciplina, de um programa ou de uma proposta específica de formação. Preocupam-se sobretudo com a avaliação do currículo desses cursos ou com seu funcionamento, para o que coletam opiniões e pontos de vista de diferentes agentes, por meio de questionários e entre- 
vistas. Como são estudos voltados ao conhecimento de realidades locais, baseadas em opiniões de um grupo restrito de sujeitos, deixam abertas muitas indagações sobre aspectos abrangentes da formação docente, como por exemplo que processos e práticas de formação seriam mais efetivos no contexto atual da educação brasileira e que políticas deveriam ser formuladas para aperfeiçoar cada vez mais tais práticas e processos.

\section{Oque dizem os artigos de periódicos?}

Foram analisados um total de 115 artigos publicados no período de 1990-97, em dez periódicos selecionados com base nos critérios de expressividade e acessibilidade, considerando-se a importância da instituição divulgadora e sua circulação nacional.

O periódico que concentrou maior número de artigos sobre formação docente foi os Cadernos de Pesquisa da Fundação Carlos Chagas, com um total de 24 (21\%), seguido por Revista Brasileira de Estudos Pedagógicos, com 19 artigos (16,5\%), Tecnologia Educacional, com 16 (14\%), Revista da Faculdade de Educação da USP, com 12 (10,5\%), Teoria e Educação, com 10 (8,5\%), Cadernos Cedes, com 9 (8\%), Educação e Realidade, com 8 (7\%), Educação \& Sociedade, com 7 (6\%), Em Aberto, com 7 (6\%) e Revista Brasileira de Educação, com 3 artigos (2,5\%).

Os temas mais enfatizados nos periódicos foram: identidade e profissionalização docente, com 33 artigos (28,7\%); formação continuada, com $30(26 \%)$; formação inicial, com $27(23,5 \%)$ e prática pedagógica, com 25 (22\%). Note-se que a distribuição dos artigos pelos quatro temas foi muito mais equilibrada do que nas pesquisas dos discentes, que evidenciou grande concentração na categoria formação inicial. Note-se ainda que o tema mais freqüente nos artigos é o que aparece em último lugar na produção dos discentes.

Os conteúdos incluídos no tema identidade e profissionalização docente são: condições de trabalho e remuneração/socialização (14), questões de gênero (11), organização política/sindical (5) e políticas educacionais (3). Os aspectos que nas pesquisas discentes são abordados de forma tímida e incipiente ganham, nos artigos, destaque e prioridade.

$\mathrm{Na}$ categoria formação continuada estão incluídos os textos que abordam: a atuação do professor nas escolas de Ensino Fundamental e 
Médio (9); os conceitos e significados atribuídos à formação continuada (7); o uso da tecnologia de comunicação (4); a educação continuada e o desenvolvimento social (3); o levantamento da produção científica sobre o tema (2); o ensino superior (2); o papel da pesquisa na formação (2), e as políticas públicas (1).

Podem-se resumir os conteúdos dos textos sobre formação continuada em torno de três aspectos: a concepção de formação continuada, propostas dirigidas ao processo de formação continuada e o papel dos professores e da pesquisa nesse processo. O conceito predominante de formação continuada nos periódicos analisados é o do processo críticoreflexivo sobre o saber docente em suas múltiplas determinações. Em sua maioria, as propostas são ricas e abrangentes, indo além da prática reflexiva, envolvendo o enfoque político-emancipatório ou críticodialético. Nos artigos dos periódicos, o professor aparece como centro do processo de formação continuada, atuante como sujeito individual e coletivo do saber docente e participante da pesquisa sobre a própria prática.

$\mathrm{Na}$ categoria formação inicial incluem-se os artigos que abordam o conjunto das licenciaturas (14), a escola Normal (7) e o curso de pedagogia (6). Nota-se aqui uma diferença em relação às pesquisas dos discentes que priorizam a escola Normal, mas nota-se também uma semelhança, já que ambos enfatizam a licenciatura e quase não investigam o curso de pedagogia.

Os conteúdos focalizados nos textos sobre a formação inicial gravitam em torno de seis eixos principais: a) a busca da articulação entre teoria e prática ou a busca da unidade no processo de formação docente; b) a necessidade de integração entre o Estado, as agências formadoras e as agências contratantes de profissionais de educação para a implementação de políticas públicas e de um projeto nacional de educação alicerçado na formação profissional, na participação docente e na valorização do magistério; c) a construção da competência profissional, aliada ao compromisso social do professor, visto como intelectual crítico e como agente da transformação social; d) a ruptura com a fragmentação e o isolamento instituído entre o curso de pedagogia e as demais licenciaturas; e) o caráter contínuo do processo de formação docente, e f) o importante papel da interdisciplinaridade nesse processo.

Sob a égide da perspectiva dialética, as alternativas apresentadas para a reconstrução dos cursos de formação de profissionais da educação 
enfatizam as espirais teoria-prática-teoria e ação-reflexão-ação. Evidenciase ainda que a formação inicial não se encerra em si mesma, devendo, portanto, articular-se com diferentes esferas da formação e da práxis dos professores em suas dimensões acadêmicas, sociais e políticas.

$\mathrm{Na}$ categoria prática pedagógica foram considerados os artigos que focalizam a escola (11), a sala de aula (9) e as relações escola/sociedade (5).

Os textos sobre a práxis do professor, analisada da perspectiva da escola, evidenciam as seguintes questões: a) contradições entre a teoria e a prática, ou seja, contradições entre o discurso e a prática do professor e entre a produção acadêmico-pedagógica e a realidade da prática escolar; b) organização do trabalho escolar e a autonomia do professor; c) escola e cultura, e d) a investigação da sabedoria docente e do cotidiano escolar.

Os artigos dirigidos ao cotidiano da sala de aula abordam três tipos de questões: a) aspectos ideológicos e teórico-filosóficos da prática docente; b) as bases teórico-metodológicas do processo de ensino; c) a construção do saber docente, e d) a pesquisa pelo próprio professor.

As análises da prática do professor em suas relações com o conjunto da sociedade evidenciam os seguintes pontos: a) políticas neoliberais e educação; b) fracasso escolar versus responsabilidade docente; c) relações entre a educação e a cultura; d) ciência versus profissão docente (a construção da sabedoria docente), e e) a construção de práticas educativas emancipatórias.

Os textos sobre a prática do professor enfeixam os seguintes elementos interpenetrados: a) as bases de sustentação ideológica e teóricofilosófica; b) a centralidade dos saberes construídos e pesquisados no cotidiano da sala de aula e da participação do professor na espiral ação-reflexão-ação; c) a importância da epistemologização dos saberes docentes; d) as contradições entre o discurso e a prática; e) as implicações da formação continuada para a transformação das práticas pedagógicas; f) o distanciamento entre a pesquisa e a prática (cientista versus professor); g) a organização do trabalho na escola e a questão da autonomia docente; h) o papel da escola no atendimento à diversidade cultural, e i) a escola e os professores no processo de transformação social.

Note-se que de maneira geral o discurso dos periódicos é bastante ideologizado e politizado, abrangendo aspectos amplos e variados da 
formação docente, definindo concepções, práticas e políticas de formação. Já as dissertações e teses revelam preocupações com temas e conteúdos bem específicos, de natureza técnico-pedagógica, deixando em aberto questões mais abrangentes sobre ações e sobre políticas de formação.

\section{Oque revelam os trabalhos do GT Formação de Professores da Anped?}

Um total de 70 trabalhos apresentados no GT Formação de Professores da Anped, no período 1992-98, constituiu a principal fonte de referência para a presente análise. Seguindo os critérios da Anped, para serem enquadrados na categoria "Trabalhos", os textos devem fazer referência a resultados de pesquisas teóricas ou empíricas, evidenciando elaboração teórica e rigor conceitual de análise.

Os principais temas abordados nesses textos foram: formação inicial, com um total de 29 textos (41\%), formação continuada, com 15 textos (22\%), identidade e profissionalização docente, com 12 textos (17\%), prática pedagógica, com 10 textos (14\%) e revisão de literatura, com 4 textos (6\%). Note-se que, como nas pesquisas dos discentes, a formação inicial concentra o maior número de trabalhos. Nos periódicos, no entanto, esse tipo de formação não tem o mesmo destaque.

Entre os trabalhos que investigam a formação inicial, 17 (58\%) focalizaram os cursos de licenciatura, $8(28 \%)$ o curso de pedagogia e 4 (14\%) o curso Normal. Verifica-se aqui uma inversão de prioridades em comparação com as pesquisas dos discentes dos programas de pós-graduação, pois aqui os cursos de licenciatura ganham mais atenção, enquanto aqueles dão prioridade ao curso Normal.

Os trabalhos sobre licenciatura discutem a dicotomia entre a formação específica e a formação pedagógica, relatam experiências curriculares inovadoras, revelam a importância da interdisciplinaridade nos programas de formação docente, expõem experiências de articulação entre ensino, pesquisa e extensão, debatem as diferenças entre conhecimento científico, saber cotidiano e saber escolar, estudam as representações e opiniões dos alunos da licenciatura.

Os trabalhos sobre o curso de pedagogia focalizam os movimentos de reformulação do curso no país; revelam as deficiências desses cursos, seja pela distância entre a proposta curricular e suas práticas, seja pela 
falta de articulação entre os docentes formadores, seja pela separação entre discurso e prática. Buscam, ainda, mostrar o peso das representações relacionadas à experiência familiar na relação professor-aluno.

Dos textos sobre o curso Normal, dois examinam o papel dos fundamentos sócio-histórico-filosóficos na formação e nas práticas das professoras das séries iniciais, um revela práticas reprodutivistas do uso do dezenho nas salas de aula do Ensino Fundamental e no curso de formação; e o outro faz um levantamento junto a 500 crianças, identificando atitudes positivas em relação ao bom desempenho em matemática quando as professoras gostavam da matéria.

Nos textos analisados, a formação continuada é concebida como formação em serviço, enfatizando o papel do professor como profissional e estimulando-o a desenvolver novos meios de realizar seu trabalho pedagógico com base na reflexão sobre a própria prática. Os textos argumentam que, nessa perspectiva, a formação deve se estender ao longo da carreira e deve se desenvolver, preferencialmente, na instituição escolar. Dois trabalhos dedicam-se às políticas de formação continuada, um deles analisando projetos de uma instituição de Ensino Superior e o outro, as políticas de formação do governo argentino.

Os estudos sobre a prática pedagógica caminham em três direções: a) análise de experiências de sala de aula, usando enfoques construtivistas ou investigando práticas avaliativas; b) análise das contradições entre o discurso e as práticas docentes; e c) registro de trajetórias autoformativas de aperfeiçoamento profissional e de construção de conhecimento prático sobre o ensino.

Outra categoria dos trabalhos do GT Formação de Professores é a de revisão de literatura, que inclui os estudos do tipo estado da arte, estado do conhecimento ou "reconciliação integrativa". Consistem num balanço do conhecimento, baseado na análise comparativa de vários trabalhos, sobre uma determinada temática.

Dos quatro trabalhos analisados nessa categoria, dois fazem uma análise da produção do GT Formação de Professores desde sua criação, em 1983, até 1997, um faz um balanço das dissertações e teses sobre formação docente, produzidas nos programas de pós-graduação em educação de 1990 a 1995, e o outro analisa o discurso de periódicos sobre o tema da articulação universidade-escola básica. 
A análise do conteúdo de 115 artigos publicados em dez periódicos nacionais, de 284 dissertações e teses produzidas nos programas de pós-graduação em educação e de 70 Trabalhos apresentados no GT Formação de Professores da Anped, na década de 1990, permitiu identificar uma significativa preocupação com o preparo do professor para atuar nas séries iniciais do Ensino Fundamental. Permitiu ainda evidenciar o silêncio quase total em relação à formação do professor para o Ensino Superior, para a educação de jovens e adultos, para o ensino técnico e rural, para atuar nos movimentos sociais e com crianças em situação de risco.

Ademais, permitiu verificar que são raros os trabalhos que focalizam o papel das tecnologias de comunicação, dos multimeios ou da informática no processo de formação. Mais raros ainda são os que investigam o papel da escola no atendimento às diferenças e à diversidade cultural.

Embora os artigos de periódicos enfatizem a necessidade de articulação entre teoria e prática, tomando o trabalho pedagógico como núcleo fundamental desse processo, a análise das pesquisas evidenciou um tratamento isolado das disciplinas específicas e pedagógicas, dos cursos de formação e da práxis, da formação inicial e da continuada.

Finalmente, as diversas fontes analisadas mostram um excesso de discurso sobre o tema da formação docente e uma escassez de dados empíricos para referenciar práticas e políticas educacionais.

\section{Art State of the Professionals Formation in Brazil}

ABSTRACT: This paper tries to synthesize knowledge on teacher education, taking into account the 284 dissertations and doctoral thesis completed from 1990 to 1996; 115 articles published in 10 educational periodicals, from 1990 to 1997; and 70 papers presented in the Annual meeting of Anped, from 1990 to 1998. 